\title{
Formality of the Chinese collective leadership
}

\author{
Haiying $\mathrm{Li}^{1} \cdot$ Arthur C. Graesser ${ }^{2}$
}

Published online: 12 July 2016

(C) Psychonomic Society, Inc. 2016

\begin{abstract}
We investigated the linguistic patterns in the discourse of four generations of the collective leadership of the Communist Party of China (CPC) from 1921 to 2012. The texts of Mao Zedong, Deng Xiaoping, Jiang Zemin, and Hu Jintao were analyzed using computational linguistic techniques (a Chinese formality score) to explore the persuasive linguistic features of the leaders in the contexts of power phase, the nation's education level, power duration, and age. The study was guided by the elaboration likelihood model of persuasion, which includes a central route (represented by formal discourse) versus a peripheral route (represented by informal discourse) to persuasion. The results revealed that these leaders adopted the formal, central route more when they were in power than before they came into power. The nation's education level was a significant factor in the leaders' adoption of the persuasion strategy. The leaders' formality also decreased with their increasing age and in-power times. However, the predictability of these factors for formality had subtle differences among the different types of leaders. These results enhance our understanding of the Chinese collective leadership and the role of formality in politically persuasive messages.
\end{abstract}

Keywords Formality $\cdot$ Political discourse $\cdot$ Power $\cdot$ Education level $\cdot$ Persuasion

Haiying Li

haiying.li@gse.rutgers.edu

1 Department of Educational Psychology, Rutgers University, Room 354A 10 Seminary Place, New Brunswick, New Jersey 08901-1281, USA

2 Department of Psychology and Institute for Intelligent Systems, University of Memphis, Suite 403C 365 Innovation Drive, Memphis 38152-3115, Tennessee, USA
Formality is a measure of linguistic and discourse complexity and style that varies with content, discourse genre, and the extent to which common ground is shared between the writer/speaker and the reader/listener (Graesser et al., 2014; H. Li et al., 2016). Formal discourse tends to occur in wellprepared spoken or written texts in which there is a need to be precise, coherent, accurate, and persuasive to an educated audience (Graesser et al., 2014; H. Li et al., 2016). Informal discourse is at the opposite end of the continuum, and is prominent in unprepared oral conversations, personal letters, and narrative texts, which are replete with pronouns, deictic references (e.g., here, there), verbs, embodiment words (e.g., health, body), and reliance on common ground (Graesser et al., 2014; H. Li et al., 2016).

The formality dimension of political discourse is diagnostic of socially significant meaning, such as authority, persuasion, politeness, solidarity, and intimacy (Brennan \& Clark, 1996; Brown \& Levinson, 1978; Dowell, Windsor, \& Graesser, 2015; H. Li et al., 2016; Stephan, Liberman, \& Trope, 2010; van Dijk, 1998). For example, Dowell et al. (2015) reported that autocratic leaders, such as Fidel Castro (Cuba), Mao Zedong (China), and Hosni Mubarak (Egypt), tended to use formal discourse during the times of crises for the purpose of persuasion, whereas they tended to use informal discourse during the times of noncrisis. They also found that the formality of the discourse of these leaders decreased over time in both crisis and noncrisis times, but this attenuation was less prominent during crisis periods. H. Li et al. (2016) reported that Mao Zedong used more formal discourse in official reports, military telegrams, published articles, and public speeches. In comparison, his discourse was more informal in personal letters, comments, and conversations. The former genres are less involved in interactions with a particular audience, compared with the latter genres.

Even though previous studies indicated that leaders' formality varied substantially across genres (H. Li et al., 2016) 
and crises (Dowell et al., 2015), no studies have longitudinally investigated the language formality of generations of leaders faced with various types of social change. In the present study, we examined the formality of the past four generations of the Chinese collective leadership (1921-2012) as a function of power phase (before vs. in power), power duration (short, medium, or long), the nation's education level, and age. The collective leadership is a Chinese political system that is very different from autocratic leadership. The collective leadership involves more factional competition for power, influence, and control over policy, such as decisions by votes in leadership groups rather than by one, autocratic individual leader (L. Cheng, 2012).

The present study advances research on political language and discourse in four major ways. First, we investigated some major predictors of political discourse, such as power-related factors, the nation's education level, and age. This is the first study that has examined leaders' formality as a function of these factors as well as differences among leaders and social contexts. This multiple factor approach provides a broader view of leaders' use of language rather than being limited to one particular factor, such as crises (Dowell et al., 2015) or disasters. Second, the formality of leaders' discourse is a potential predictor of political and social events. Previous studies had demonstrated that formality may predict crises (Dowell et al., 2015) and genres (H. Li et al., 2016), whereas this study expands to other social and political changes. For example, when a leader's formality dramatically changes from his or her normal discourse style, the formality change may be diagnostic of some potential unexpected events, civil discontent, war, the stability of the economy, or changes in the stock market. Third, our study pursues both a longitudinal and crosssectional approach to examine the leaders' use of language and thereby provides a more comprehensive and accurate forecast of the social and political changes, as compared with the approach that considers only one particular leader at particular periods. Fourth, this study applies an automated measure of formality (a Chinese formality score; H. Li et al., 2016), a metric based on advances in computational linguistics (see the Method section for details), to study the leaders' language style as a function of power phase, education, power duration, and age. This automated formality measure will speed up the research on political discourse and other types of Chinese discourse on the large repositories of texts rather resorting to manually coding by humans, which is beset with high effort, costs, and questionable reliability.

Power is obviously a central construct in studies of political discourse. Power struggle typically occurs before political leaders come into power, whereas power maintenance is a second phase after they gain power. In both phases, leaders have to sell their guidelines, policies, and ideology through persuasive speeches to the public, their followers, or their higher leading organizations. In addition, leaders allegedly consider the audience's comprehension proficiency and the shared common ground with the audience (Clark, 1996) in their persuasive discourse and adopt the appropriate language style (Bell, 1984) to reach their persuasion goals. With these considerations in mind, we investigated the linguistic patterns of the formality of four generations of the Chinese collective leaderships in terms of their power phase, power duration, the nation's education level, and age.

The data were interpreted from the lens of a theoretical persuasion framework called the elaboration likelihood model (ELM; Petty \& Cacioppo, 1984, 1986; Petty, Cacioppo, Strathman, \& Priester, 2005). ELM assumes a dual processing model with two routes to persuasion: a central route versus a peripheral route. The central route occurs when the speaker or writer carefully and thoughtfully considers the accuracy, evidence, reasoning, and conceptual merits of the information presented in support of a position. Elaboration in a persuasion text is the extent to which the speaker/writer expresses issuerelevant arguments in a message. In contrast, the peripheral route occurs when the speaker relies on simple cues or messages to persuade the audience, such as the attractiveness of the speaker, humor, and the frequency of presenting the message, without scrutinizing the conceptual merits of the presented information. The motivation and efforts for processing the message determines which route the speaker selects. For example, the peripheral route tends to be adopted when the speaker and/ or audience are least motivated, devote the minimum amount of effort, or have low ability (Fiske \& Taylor, 1984).

These two processing routes are reflected by different linguistic and discourse features. For instance, the messages conveyed via the central route have more formal discourse characteristics, such as being in the informational expository genre, with coherent logical reasoning, precisely selected words, and sentences that are syntactically and semantically complex. In contrast, the messages conveyed via the peripheral route take on the characteristics of informal discourse that is associated with everyday conversation and the narrative genre, with frequent words and simple syntax (Allen \& Preiss, 1997; Graesser et al., 2014; Jae, 2010; Kaakinen, Salonen, Venäläinen, \& Hyönä, 2011; Lee \& Leets, 2002). Political leaders are expected to vary in their use of the central versus the peripheral routes as a function of power phase, the nation's education level, power duration, and age.

From the standpoint of political science, Arendt (1970) proposed that power never belongs to any individual, but to a group. That is, power exists only to the extent that the group stays together and recognizes the stature of the leader. When somebody is already in power, the person is empowered by a number of people to act in their name. The leader may or may not have the burden to convince important stakeholders to support the leader's position. The ideal leader would strategically adopt the central route when the stakeholders are educated and possibly questioning policy decisions. The ideal 
leader could resort to the peripheral route when the stakeholders are less educated or simply trust the leader. The process of achieving power is another phase in power, however. In order to achieve power, the person would perhaps use the central route (formal language) to persuade the public, their followers, and officials in the higher organization to reach the consent for collective goals and consequently to gain the power. That depends on the audience, which may be a broader audience, including the populace, for a person to become a leader. The peripheral route may have value to the extent that a broader population needs to be convinced that an emerging leader has impact.

The question arises as to where China fits into this analysis. China has a unique political election system. It is unnecessary for the chairman candidates to make public speeches to persuade an educated or uneducated public to vote for them. Therefore, the Chinese leaders can rely on either the peripheral route or the central route during the power struggle phase, whatever works. However, educated political stakeholders need to be convinced during the power maintenance phase. Therefore, we hypothesize that the Chinese paramount political leader will increasingly use the central route after they gain power in order to persuade the powerful educated stakeholders and carry out the policies in the interest of collective goals (Parsons, 1958). On the basis of the previous literature, we therefore proposed the first hypothesis:

Hypothesis 1: Chinese political leaders will adopt a more central route to persuasion after they gain power than before they gain power. Regarding formality, discourse of leaders during in-power times will have higher formality scores than before-power times.

Previous studies (Dowell et al., 2015; Graesser et al., 2014; H. Li et al., 2016) had claimed that speakers would use formal discourse to persuasion when the audience was educated. However, the available empirical studies did not have direct support for the claim. The present study investigated whether the political leaders would tend to use the central route to persuasion for the higher-educated audience. We therefore proposed the second hypothesis:

Hypothesis 2: Chinese political leaders will use a central route to persuasion to the extent that the nation's education levels are higher. Specifically, the increasing education level for the public will be associated with an increase in the formality of leaders' discourse.

According to Clark's (1996) theory of language use, when the speaker shares more common ground with the listener, the speaker and the listener share mutual knowledge, beliefs, and suppositions. As the speaker and the listener share more common ground, the speaker tends to use more informal language, including pronouns and demonstrative references (Clark, Schreuder, \& Buttrick, 1983), and there is less of a need to have coherent discourse, because the listener can make inferences to fill the gaps. Thus, we proposed the third hypothesis:

Hypothesis 3: Chinese political leaders will use a central route to persuasion when they have a short in-power time, but with the increasing in-power times, they will use the more peripheral route to persuasion due to the more shared common ground with their colleagues, followers, and audience. The leaders' formality therefore will decrease with the increasing in-power times.

Because age is always a robust and negative predictor of formality (Dowell et al., 2015), our fourth hypothesis was:

Hypothesis 4: Chinese political leaders will use a central route to persuasion when they are young, but they will use the more peripheral route to persuasion when they are getting older. The increasing age will be associated with a decrease in the formality of leaders' discourse.

\section{Method}

\section{Corpora}

The corpora for the Chinese collective leadership consisted of four generations of the leadership of the Communist Party of China (CPC): Mao Zedong, Deng Xiaoping, Jiang Zemin, and $\mathrm{Hu}$ Jintao. These four leaders held the offices of General Secretary or Advisory of the CPC, Chairman of the People's Republic of China (PRC), and Chairman of the Central Military Commission. These leaders represented the paramount political leaders under the Chinese collective leadership over time. Their language style reflects the characteristics of the political discourse under the leadership of the CPC over time. The sample for the present study included a collection of original Chinese political speeches and writings produced by these four leaders between 1921 and 2012 across almost a century (92 years) $(N=1662)$. Their speeches and writings represent the ideology of their generations of the CPC under their leadership.

Chairman Mao Zedong is considered as the leader of the first generation, between 1945 and 1976 (Liao, 2012). He and his colleagues established the PRC in 1949 and then consolidated socialist system in China. Before 1949, the CPC under Mao's leadership struggled for power against Kuomintang led by Chiang Kai-shek, the paramount leader of the Republic of China (ROC), the predecessor of the PRC (J. Li \& Wang, 2008). After 1949, Mao and his group made great endeavors to maintain the CPC's power as Chiang and other parties 
struggled for power. Generally speaking, the first generation concentrated on the struggle for power for the CPC against other parties, with the guidance of Mao Zedong Thought. Mao's corpus consisted of 1,158 Chinese texts delivered between 1921 and 1975. They were collected from the Selected Works of Mao Zedong (Mao, 1977, 1991) and the Collected Works of Mao Zedong (Mao, 1993, 1996, 1999). If the text occurred in both works, the one in the Collected Works was adopted into the corpus.

Chairman Deng Xiaoping, the leader of the second generation, between 1978 and 1992 (Song, 1999), was called the chief architect of Reform and Opening Up. He and his group aimed to carry out economic reform and develop the socialist market economy (J. Li \& Wang, 2008). This generation was in the early period of the consolidation of the CPC power. Deng's corpus consisted of 221 texts delivered between 1938 and 1992, collected from the Selected Works of Deng Xiaoping (Deng, 2004).

Chairman Jiang Zemin was considered as the leader of the third generation, between 1992 and 2002 (Lei, 1997). He and his colleague proposed a theory called "Three Represents"a socio-political ideology that the CPC should be representative of advanced productive forces, advanced culture, and the interests of the overwhelming majority of the Chinese people, with the concentration on the stabilization and development of the market economy. Jiang's corpus consisted of 203 texts delivered between 1978 and 2004, collected from the Selected Works of Jiang Zemin (Jiang, 2006).

Chairman Hu Jintao was considered as the leader of the fourth generation, between 2002 and 2012 (Wang, 2005). $\mathrm{He}$ and his colleagues proposed the development of a harmonious society and promoted the Scientific Development Concept. Hu's corpus consisted of 80 texts delivered between 2002 and 2012, which were collected online. The third and fourth generations were in the mature period of the consolidation of the CPC's power.

\section{Text processing}

The texts of these four leaders were edited before publication by the editorial committee on the Party Literature Research Center of the Communist Party of China's Central Committee. Editors were faithful to their original ideas, and avoided polishing their language in the process of editing. Editors corrected the typos, dropout-characters, redundant characters, and incorrect punctuations. They also conducted technical processing for spoken texts. Thus, the revision problems from editors (see van Dijk, 1997) were assumed minimal. We assume that their texts were reasonably objective depictions of their language styles, but acknowledge that there is no guarantee.

All analyses were conducted on the original simplified Chinese texts of these leaders. The genres consisted of official documents, military telegrams, published articles, public speeches, conversations (the leader as the sole speaker), letters, and comments. Information that was not part of the actual discourse (e.g., audience reaction, editor comments, title, signature) was removed in a cleaning process. Each text was separated or integrated by date on which it was originally delivered rather than by topics as editors organized.

\section{Measure of formality}

Different computational linguistic models were used to measure formality, ranging from word level (Fang \& Cao, 2009; Heylighen \& Dewaele, 2002) to the multiple textual levels (Graesser et al., 2014; H. Li, Q. Cheng, \& Graesser, 2015; H. Li, Graesser, \& Cai, 2013; H. Li et al., 2016). Recently, the researchers compared these measures in both English (Graesser et al., 2014; H. Li et al., 2015; H. Li et al., 2013) and Chinese (H. Li et al., 2016) languages. They found that formality metrics that were measured at the multiple textual levels were more robust. Since the texts in the present study are in Chinese, the measure of formality at the multitextual level constructed for the Chinese language is briefly described below.

H. Li et al. (2016) constructed a weighted Chinese formality score (called WCF-score) based on humans' perception of formality construct. Formality increases with high occurrence of cohesion and emotional words (negative and positive), but the low occurrence of narrativity and embodiment words. Because the WCF score was most robust than the other formality metrics, for this article we adopted the WCF score to measure these leaders' formality. The following section describes the automated computational linguistic techniques that are used to extract the linguistic and discourse features to compute the Chinese formality score.

The Chinese formality score is based on features extracted from Linguistic Inquiry and Word Count (LIWC; Pennebaker, Booth, \& Francis, 2007) along with two measures of discourse cohesion: semantic overlap of adjacent sentences, based on latent semantic analysis (LSA; Jurafsky \& Martin, 2009; Landauer, McNamara, Dennis, \& Kintsch, 2007), and content word overlap (CWO). LIWC is a text analysis program with a text processing module and a dictionary, which classifies words into dozens of linguistic and psychological categories based on the ratings of human experts (Pennebaker et al.,2007). The Chinese LIWC dictionary in this study was based on the 2007 English dictionary, which displayed high reliabilities (Huang et al., 2012). The simplified Chinese LIWC provides 71 measures (H. Li, Cai, Graesser, \& Duan, 2012; H. Li et al., 2016), including linguistic (e.g., pronouns, verbs), psychological (e.g., affect, cognition), personal concerns (e.g., work, religion), and paralinguistic (assents, fillers).

H. Li et al. (2016) conducted a principal component analysis (PCA) on a large corpus of Chinese texts. The PCA uncovered seven orthogonal dimensions that accounted for $58 \%$ 
of the variance in a large Chinese corpus of 4,679 texts with 25,184,754 words in total (H. Li et al., 2012; H. Li et al., 2016). These dimensions align with multilevel theoretical frameworks of language and discourse that differentiate structures, strategies, and cognitive processes at different levels of language and discourse (Graesser \& McNamara, 2011; Kintsch, 1998). The seven PCAs are listed and succinctly defined below:

Processes-procedures-planning (PPP) PPP includes texts that (1) describe actions and events in procedures or processes or (2) forecast events, goals, plans, or recommendations.

Narrativity Narrative texts tell a story with characters and events, which are closely affiliated with everyday oral conversation.

Space-time Space-time has texts with many words that are associated with time, space, location, and motion.

Cohesion The extent to which discourse contains explicit words and ideas that overlap across sentences, paragraphs, and the entire text.

Embodiment Texts have many words that describe biologyrelated topics, such as body, ingest, health, sex, and feeling.

Positive emotion Texts have words that express positive emotions, such as satisfaction, relax, joy, and leisure.

Negative emotion Texts have words that express negative emotions, such as anger, anxiety, and sadness.

These seven dimensions were used to construct a formality score based on human formality score from 1 (least formal) to 6 (most formal) (see H. Li et al., 2016, for details). Equation 1 shows that the formality metric with 4.32 (more formal; with 1 indicating most informal and 6 most formal) as the constant increases with the high cohesion, negative emotion, and positive emotion (positive coefficients), but with the low occurrence of narrativity and embodiment (negative coefficients), whereas the other two dimensions (PPP and space-time) did not significantly predict the formality as humans perceived (H. Li et al., 2016). Thus, five dimensions were used to compute one composite measure of formality as in Eq. 1 (H. Li et al., 2016):

$$
\begin{aligned}
& \text { Formality }=4.32+.24 \times \text { Cohesion }+.14 \\
& \times \text { Negative Emotion }+.05 \times \text { Positive Emotions }-.34 \\
& \times \text { Narrativity }-.23 \times \text { Embodiment }
\end{aligned}
$$

In this study, all of the texts were analyzed with the Chinese LIWC, LSA, and CWO tools, and computed the normalized component scores based on the PCA component scores described in H. Li et al.'s article (2016). The formality of each text was then computed with five components described in Eq. 1. The standardized formality scores were used in the analysis $(M=0, S D=1)$. This formality measure not only robustly predicted human formality judgments, but also best captured the genres in the political discourse generated by Chinese political leaders (H. Li et al., 2016). Thus, we assume the Chinese formality score is an appropriate measure for these four leaders' speeches and writings.

\section{Measure of power phase}

Struggling for power is an essential and ultimate goal for political leaders (Chilton \& Schäffner, 2002). In many countries, the time duration when political leaders gain power should be quantitatively similar to the time when they are in office. However, in China it is more complicated. Some political leaders worked as premier political leader of the nation, the CPC, and the Army, but their in-office dates for these three positions were not the same. Another exception is Deng Xiaoping. In his life, he was never elected as the highest national leader officially, but he was regarded as the supreme leader or head of state in his era. Thus, this study used inpower dates to code power phase.

For each leader, we coded power phase into two levels: before power (before achieving power) and in power (after achieving power). Mao was in power between June 11, 1945 and September 9, 1976 (Liao, 2012). His texts before June 11, 1945, were coded as "before power," and those between 1945 and 1976 were coded as "in power." Similarly, Deng was in power between December 23, 1978, and October 18, 1992 (Song, 1999); Jiang, between October 19, 1992, and November 14, 2002 (Lei, 1997); and Hu, between November 15, 2002, and November 14, 2012 (Wang, 2005). Therefore, their texts were coded as "before power" and "in power" on the basis of the dates above, respectively. The four leaders delivered the total number of 436 texts in beforepower times versus 1,226 texts in in-power times.

\section{Measure of education level}

We coded education level according to the enrollment rate of the 4-year and 2-year college students (hereafter called the college enrollment rate). The enrollment rate $(1 / 10,000)$ was the ratio of the number of the enrolled college students in a year to the number of the nation's population of that year and then multiplied by 10,000 . Considering the enrollment usually starts from September 1, we used the academic school year as a unit for both the population and enrollment data. Appendixes A and B list the resources of the population data and college enrollment data, respectively. The missing data were replaced by the average of the number of population and college enrollment in the previous and the succeeding years. 
The college enrollment rate was used to estimate the nation's education level for the following three reasons. First, the college enrollment data are relatively complete as compared with other education data (e.g., illiteracy, K-12) and thus more accurately reflect the change in education level per year. Even during the Cultural Revolution, the colleges still "recruited" students, but changed from competitive selection to recommendation (Yang, 2005). Enrollment data are available for each year except 1921-1927, 1932-1934, 1947-1948, which enabled us to code $94 \%$ of the texts with only 106 missing data points. Second, the number of the college students indirectly reflects the number of the students at the other education levels. An increasing number of college students has an associated increase in the number of students who completed high school. Third, the college students and educated people constantly attended to concerns about politics and therefore comprised the leading audience of the political leaders (J. Li \& Wang, 2008). The college students launched several historical campaigns as the turning points in China's political history, such as the 12.9 Campaign (一二 ‘运动) in 1935 against Japan invasion, the 4.5 Campaign (四五运动) in 1976 against the Cultural Revolution, and the 6.4 Campaign (六四事件) in 1989 against inflation, unemployment, and bribery (zh.wikipedia.org). Thus, we assume that the college enrollment rate is an appropriate measure of the nation's education level.

\section{Measure of power duration}

Another two predictors are age and power duration. Power duration refers to the duration during which leaders are in power. Among these four leaders, Mao gained power for 31 years (1945-1976), Deng for 14 years (1978-1992), and Jiang (1992-2002) and $\mathrm{Hu}$ (2002-2012) for 10 years each. We coded the power duration variable into three levels, namely long, medium, and short for Mao, Deng, and Jiang and $\mathrm{Hu}$, respectively. Another reason for using the three-level power duration as a predictor is that these three periods represented three eras of the CPC power struggle and consolidation: power struggling for Mao, early power consolidation for Deng, and mature power consolidation for Jiang and $\mathrm{Hu}$ (J. Li \& Wang, 2008). A Pearson correlation between the three-level power duration variable and the four-leader variable was nearly perfect, $r=.98, p<.001$, so we adopted power duration as a predictor instead of leader. The texts at each power duration were 1,158 for Mao, 221 for Deng, and 283 for Jiang and Hu, representing three different in-power time durations, respectively.

\section{Statistical analyses}

A four-step hierarchical regression was conducted with formality as the dependent variable to examine the predictability of the four independent variables (power phase, education level, power duration, and age) for the formality of the
Chinese collective leadership. Age was entered at Step 1 to control for the individual differences (Model 1). Power duration was entered at Step 2 (Model 2), education level at Step 3 (Model 3), and power phase at Step 4 (Model 4).

Power duration was used to split the sample into three subsets: short, medium, and long. Three 3-step hierarchical regressions for these three subset data were conducted to examine whether the predictors for the Chinese collected leadership was robust for each type of leader in terms of their power duration. The variables entered in the models were ordered by age (Model 1), education level (Model 2), and power phase (Model 3) at Steps 1, 2, and 3, respectively.

\section{Results}

A series of relevant assumptions were tested before conducting of the hierarchical regression analyses. First, the sample size was deemed adequate, given four $(N=1,662)$ and three $(N \mathrm{~s}=1,158,221$, and 283) independent variables (Tabachnick \& Fidell, 2001). An examination of the correlations (see Table 1) revealed that no pair of independent variables was correlated above .70. The collinearity statistics were all within the accepted limits, tolerance was between .34 and .68 , and the variance inflation factor was between 1.48 and 2.94 (below 10); thus, the assumption of multicollinearity was satisfied (Coakes \& Steed, 2009; Hair et al., 1998). A value of Cook's distance (.02) less than 1 met the assumption of outliers. Residual and scatterplots indicated that the assumptions of normality, linearity, and homoscedasticity were all satisfied (Hair et al., 1998; Pallant, 2013).

\section{Predictors for the formality of the Chinese collective leadership}

Table 2 reports the regression statistics for four-step hierarchical regression models. The results revealed that at Step 1, age significantly and negatively contributed to the regression model, $F(1,1660)=14.70, p<.001$, accounting for $0.9 \%$ of the variance in formality. At Step 2, adding power duration explained an additional $17.1 \%$ of the variance in formality, and this change in $R^{2}$ was significant, $F(1,1659)=345.88$, $p<.001$. At Step 3, adding education level explained an additional $0.9 \%$ of the variance in formality, and this change in $R^{2}$ was also significant, $F(1,1658)=17.92, p<.001$. At Step 4 , adding power phase explained an additional $2.5 \%$ of the variance, and the $R^{2}$ change was again significant, $F(1,1657)$ $=53.05, p<.001$. All of the models were significant, and each independent variable was a significant predictor of formality in each model, except education level in Model 4, which was marginally significant ( $p=.051)$.

The final model showed that the four independent variables together accounted for $21.4 \%$ of the variance in formality. 
Table 1 Pearson correlations between the variables

\begin{tabular}{lllll}
\hline & Formality & Power Duration & Age & Education \\
\hline Power duration & $-.29^{* * *}$ & 1.00 & & \\
Age & $-.09^{* * *}$ & $-.57^{* * *}$ & 1.00 & \\
Education & $.28^{* * *}$ & $-.70^{* * *}$ & $.36^{* * *}$ & 1.00 \\
Power phase & .02 & $-.14^{* * *}$ & $.53^{* * *}$ & $.24^{* * *}$ \\
\hline
\end{tabular}

*** $p<.001$

Power duration was the most robust predictor, followed by power phase, age, and education level, according to the coefficients (see Table 2 and Eq. 2). Specifically, leaders tended to use more formal discourse when they were in power than before power and with the nation's increasing education level. Leaders' formality decreased with their increasing age and in-power times. In general, the formality scores of the leaders under the Chinese collective leadership could be computed with Eq. 2.

Formality $=3.98+.46 \times$ Power Phase $+.01 \times$ Education Level

$-.66 \times$ Power Duration- $.04 \times$ Age

The value of 3.98 is the constant indicating the overall level of formal discourse, with power phase (in power) increasing formality by .46 unit more than before power, education level increasing formality by .01 , power duration decreasing formality by .66 , and age decreasing formality by .04 .

\section{Predictors for leaders with different power durations}

The three-step hierarchical regression was performed on formality in three subsets of the data-long duration (Mao), medium duration (Deng), and short duration (Jiang and $\mathrm{Hu}$ ) using the same procedures as for the four-step hierarchical regression. The only difference was that power duration was removed from the analyses, since we used this variable to split the data. Tables 3, 4, and 5 display the regression statistics for these three analyses.

\section{Long power duration}

Model 1 showed that age robustly and negatively predicted the formality of leaders with a long power duration, $F(1,1156)=$ $99.18, p<.001$, accounting for $7.9 \%$ variance in formality. Model 2 indicated that adding education level did not show a significant $R^{2}$ change, $F(1,1155)=0.10, p>.05$. For Model 3, adding power phase explained an additional $3.1 \%$ of the variance in formality and showed a significant change in $R^{2}$, $F(1,1154)=40.45, p<.001$. All of the models were significant, and each independent variable was a significant predictor of formality except education level in Model 2 (see Table 3).

The final model showed that the three independent variables together accounted for $11.0 \%$ of the variance in the formality of Mao, who was in power for 31 years. Power phase was the most robust predictor, followed by education

Table 2 Regression analyses predicting formality of the Chinese collective leadership

\begin{tabular}{|c|c|c|c|c|c|c|c|c|}
\hline Variable & $B$ & $S E B$ & $\beta$ & $t$ & $R^{2}$ & $R^{2}$ change & $d f$ & $F$ \\
\hline Step 1 & & & & & .009 & $.009^{* * * *}$ & 1,1660 & $14.70^{* * *}$ \\
\hline (Constant) & 0.49 & 0.13 & & $3.77^{* * * *}$ & & & & \\
\hline Age & -.01 & .00 & -.09 & $-3.83^{* * *}$ & & & & \\
\hline Step 2 & & & & & .180 & $.171^{* * *}$ & 2,1659 & $181.82^{* * *}$ \\
\hline (Constant) & 3.65 & 0.21 & & $17.60^{* * *}$ & & & & \\
\hline Age & -.03 & .00 & -.38 & $-14.04^{* * *}$ & & & & \\
\hline Duration & -.65 & .04 & -.50 & $-18.60^{* * *}$ & & & & \\
\hline Step 3 & & & & & .189 & $.009^{* * *}$ & 3,1658 & $128.42^{* * *}$ \\
\hline (Constant) & 3.23 & 0.23 & & $14.08^{* * *}$ & & & & \\
\hline Age & -.03 & .00 & -.37 & $-13.78^{* * * *}$ & & & & \\
\hline Duration & -.53 & .05 & -.41 & $-11.49^{* * *}$ & & & & \\
\hline Education & .01 & .00 & .13 & $4.23^{* * *}$ & & & & \\
\hline Step 4 & & & & & .214 & $.025^{* * *}$ & 4,1657 & $112.60^{* * * *}$ \\
\hline (Constant) & 3.98 & 0.25 & & $16.03^{* * *}$ & & & & \\
\hline Age & -.04 & .00 & -.51 & $-15.62^{* * *}$ & & & & \\
\hline Duration & -.66 & .05 & -.51 & $-13.53^{* * *}$ & & & & \\
\hline Education & .01 & .00 & .06 & $1.96^{\dagger}$ & & & & \\
\hline Power phase & .46 & .06 & .20 & $7.28^{* * *}$ & & & & \\
\hline
\end{tabular}

$N=1,662$. Duration $=$ power duration. ${ }^{* * *} p<.001,{ }^{\dagger} p<.10$ 
Table 3 Regression analyses predicting formality of leaders with a long power duration

\begin{tabular}{|c|c|c|c|c|c|c|c|c|}
\hline Variable & $B$ & $S E B$ & $\beta$ & $t$ & $R^{2}$ & $R^{2}$ change & $d f$ & $F$ \\
\hline Step 1 & & & & & .079 & $.079^{* * * *}$ & 1,1156 & $99.18^{* * *}$ \\
\hline (Constant) & 1.85 & 0.20 & & $9.25^{* * *}$ & & & & \\
\hline Age & -.04 & .00 & -.28 & $-9.96^{* * *}$ & & & & \\
\hline Step 2 & & & & & .079 & .000 & 2,1155 & $49.60^{* * *}$ \\
\hline (Constant) & 1.80 & 0.27 & & $6.75^{* * *}$ & & & & \\
\hline Age & -.03 & .01 & -.27 & $-6.15^{* * *}$ & & & & \\
\hline Education & -.02 & .07 & -.01 & -0.31 & & & & \\
\hline Step 3 & & & & & .110 & $.031^{* * * *}$ & 3,1154 & $47.68^{* * *}$ \\
\hline (Constant) & 2.11 & 0.27 & & $7.91^{* * *}$ & & & & \\
\hline Age & -.05 & .01 & -.35 & $-7.81^{* * *}$ & & & & \\
\hline Education & -.16 & .07 & -.10 & $-2.18^{*}$ & & & & \\
\hline Power phase & .54 & .09 & .24 & $6.36^{* * * *}$ & & & & \\
\hline
\end{tabular}

$N=1,158 .^{* * *} p<.001,{ }^{*} p<.05$

level and age (see Table 3 and Eq. 3). Specifically, leaders tended to use more formal discourse when they were in power than before power, but they tended to use more informal discourse with increasing education level of the country and age. In general, the formality scores for Mao, with his long power duration, could be computed with Eq. 3 .

$$
\begin{aligned}
& \text { Formality }=2.11+.54 \times \text { Power Phase }-.16 \\
& \quad \times \text { Education Level }-.05 \times \text { Age }
\end{aligned}
$$

\section{Medium power duration}

The formality of leaders with a medium power duration showed a different pattern from that of Mao, with a long power duration. Age was a robust predictor of formality, $F(1,219)=24.30, p<$ .001 . Adding education level in Model 2 explained an additional
$1.2 \%$ of variance in formality, but the $R^{2}$ change was not quite significant, $F(1,218)=2.89, p=.09$. Adding power phase in Model 3 explained an additional $0.4 \%$ of variance, and again the $R^{2}$ change was not significant, $F(1,217)=0.87, p>.05$.

As is shown in Table 4, all of the models were significant, but only age was a significant predictor in each model. Thus, we adopted Model 1, which explained $10 \%$ of the variance in formality. Specifically, Deng's formality decreased with increasing age. The formality scores for Deng, with his medium power duration, could be computed with Eq. 4.

Formality $=0.72-.02 \times$ Age

\section{Short power duration}

The formality of leaders with short power durations showed a different pattern from those with long and medium power

\begin{tabular}{|c|c|c|c|c|c|c|c|c|}
\hline Variable & $B$ & $S E B$ & $\beta$ & $t$ & $R^{2}$ & $R^{2}$ change & $d f$ & $F$ \\
\hline Step 1 & & & & & .100 & $.100^{* * * *}$ & 1,219 & $24.30^{* * *}$ \\
\hline (Constant) & 0.72 & 0.23 & & $3.13^{* *}$ & & & & \\
\hline Age & -.02 & .00 & -.32 & $-4.93^{* * *}$ & & & & \\
\hline Step 2 & & & & & .112 & $.012^{\dagger}$ & 2,218 & $13.70^{* * *}$ \\
\hline (Constant) & 1.09 & 0.32 & & $3.45^{* * *}$ & & & & \\
\hline Age & -.02 & .01 & -.48 & $-4.12^{* * *}$ & & & & \\
\hline Education & .06 & .04 & .20 & $1.70^{\dagger}$ & & & & \\
\hline Step 3 & & & & & .115 & .004 & 3,217 & $9.42^{* * *}$ \\
\hline (Constant) & 1.16 & 0.33 & & $3.57^{* * *}$ & & & & \\
\hline Age & -.02 & .01 & -.51 & $-4.22^{* * *}$ & & & & \\
\hline Education & .03 & .05 & .10 & 0.65 & & & & \\
\hline Power phase & .19 & .20 & .14 & 0.93 & & & & \\
\hline
\end{tabular}

Table 4 Regression analyses predicting formality of leaders with a medium power duration

$N=221 .{ }^{* * *} p<.001,{ }^{* *} p<.01,{ }^{\dagger} p<.10$ 
Table 5 Regression analyses predicting formality of leaders with a short power duration

\begin{tabular}{|c|c|c|c|c|c|c|c|c|}
\hline Variable & $B$ & $S E B$ & $\beta$ & $t$ & $R^{2}$ & $R^{2}$ Change & $d f$ & $F$ \\
\hline Step 1 & & & & & .000 & .000 & 1,281 & 0.01 \\
\hline (Constant) & 0.84 & 0.47 & & $1.76^{\dagger}$ & & & & \\
\hline Age & .00 & .01 & .00 & -0.07 & & & & \\
\hline Step 2 & & & & & .083 & $.083^{* * *}$ & 2,280 & $12.62^{* * *}$ \\
\hline (Constant) & 0.21 & 0.47 & & 0.45 & & & & \\
\hline Age & .01 & .01 & .05 & 0.84 & & & & \\
\hline Education & .01 & .00 & .29 & $5.02^{* * *}$ & & & & \\
\hline Step 3 & & & & & .083 & .000 & 3,279 & $8.38^{* * *}$ \\
\hline (Constant) & 0.21 & 0.53 & & 0.39 & & & & \\
\hline Age & .01 & .01 & .05 & 0.69 & & & & \\
\hline Education & .01 & .00 & .29 & $4.33^{* * *}$ & & & & \\
\hline Power phase & -.00 & .13 & .00 & -0.02 & & & & \\
\hline
\end{tabular}

$N=283 .^{* * *} p<.001,{ }^{\dagger} p<.10$

durations. Age did not predict formality in Model 1, $F(1,281)$ $=0.01, p>.05$. Adding education level in Model 2 explained an additional $8.3 \%$ of the variance in formality and showed a significant $R^{2}$ change, $F(1,280)=25.23, p<.001$. Adding power phase in Model 3 did not add any additional variance in formality, so the $R^{2}$ change was not significant, $F(1,279)=$ $.00, p>.05$.

As is shown in Table 5, Model 1 was not significant, but Models 2 and 3 were significant. In Models 2 and 3, only education level was a robust predictor. Thus, we adopted Model 2, which explained $8.3 \%$ of the variance in formality. The leaders' formality increased with the nation's increasing education level. The formality scores for leaders with a short power duration could be computed with Eq. 5 .

Formality $=0.21+.01 \times$ Education Level

\section{Discussion}

China has a unique political election system, in the sense that the chairman candidates do not make public speeches before voting. China has been led by leaders of five generations under the Chinese collective leadership for about seven decades. However, no studies have longitudinally investigated the language formality of leaders faced with various types of social changes. In this study, we examined the formality of the past four generations of the Chinese collective leadership (1921 -2012) in terms of power phase, education level, power duration, and age. This section discusses the predictability of these four predictors, first for the formality of leaders under the Chinese collective leadership, and then for the formality of leaders with different power durations.

\section{Age}

The results showed that age alone or along with three other factors was a robust negative predictor of the formality of leaders under the Chinese collective leadership. The same pattern occurred for leaders with medium (Deng) and long (Mao) power durations, but not for leaders with short power durations (Jiang and $\mathrm{Hu}$ ). One possible explanation is that age may robustly predict leaders' formality when the leaders' ages cross the threshold into their 80 s, when aging takes its toll on cognitive capacity. Another possible explanation is that age may be a robust predictor of leaders' formality when their age spans different stages of age. For example, Mao's speeches were produced from the ages of 28 to 82 , and Deng's from 34 to 88 , ranging from youth to very old age. The long spans and different stages of age make age's predictability for formality more manifest. In contrast, leaders with a short power duration delivered their speeches from the ages of 52 to 76, only in their middle years. This short range within one stage of age clearly reduced the function of age in formality. Thus, our results support the claim that aging decreases political leaders' formality (Dowell et al., 2015), but primarily when their age spans cross different stages of life, such as youth to middle age to old age. When Chinese political leaders grow older, they tend to shift from the central to the peripheral route, but this effect is sensitive to age transition and durations.

\section{Power duration}

These results revealed that power duration substantially explained most of the variance in formality, as compared to the other predictors. Specifically, the longer that leaders were in power, the more informal discourse they tended to use. The leaders with longer power durations established more shared 
common ground with their fellow leaders and followers, as well as with the populace. Therefore, they tended to increasingly use the peripheral route to persuasion. Mao (31 in-power years) used more informal discourse than Deng (14 in-power years), allegedly because he shared more common ground with the audience than did Deng. Similarly, Deng used more informal discourse than either Jiang and $\mathrm{Hu}$ (10 in-power years) for the same reason.

How is it possible that the 4-year (short vs. medium) and 17-year (medium vs. long) differences predicted the same degrees of formality change? Perhaps the formality change could be explained by the unique situation for Deng. Even though Deng was in power only for 14 years, he participated in the Communist revolution in 1926, only 6 years later than Mao. He also participated in two civil wars, the Anti-Japanese Wars, and the early development of China's economy. Even though his power duration is only 4 years more than those of Jiang and $\mathrm{Hu}$, his long years of top leadership in the CPC afforded him the opportunity to share more common ground than either Jiang or $\mathrm{Hu}$, who had no such experiences.

\section{Education level}

Education level was another significant predictor of the formality of leaders' language under the Chinese collective leadership, whether it was used alone or along with the other variables. Leaders tended to use more formal discourse when a higher proportion of the population of the country received higher education. This finding provided additional empirical evidence for the claim that formal discourse is used when the audience has more educated people (Dowell et al., 2015; Graesser et al., 2014; H. Li et al., 2016). Leaders used the central route (formal discourse) to persuasion to a greater extent than the peripheral route (informal discourse) with the increasing education level of their audience.

The analysis of power duration indicated that education was not a consistent predictor, however. Education significantly and negatively predicted the formality of the leader with a long power duration, but did not significantly predict the formality of the leader with a medium power duration. Education was the only robust predictor of the formality of leaders with short power durations. One possible explanation for education level as a robust predictor of the formality of Jiang and $\mathrm{Hu}$ is that Jiang and Hu were more concerned about the populace's education when they delivered their speeches, because the portion of the population with higher education dramatically increased in their eras. In Mao's era, the college enrollment rate $(1 / 10,000)$ increased from 0.01 to 4.18 , with a range of 4.17 . In Deng's era, the rate increased from 0.01 to 6.40 , with a range of 6.39. In the eras of Jiang and $\mathrm{Hu}$, the rate increased from 1.50 to 50.09 , with the range of 48.59 . A statistical analysis showed that education level measured by enrollment rate was significantly different between leaders with a short power duration and those with medium and long durations together, $F(1,1660)=191.70, p<.001,{ }^{2}=.55$, with $M=19.26(S D=$ $14.97)$ versus $M=1.28(S D=1.42)$ for short versus the other durations, respectively. This finding demonstrates that education level is an important predictor of formality, but only when there is a sufficient range in education levels.

One possible explanation for education level not robustly predicting Deng's formality is that there were more missing data in his corpus (1937-1942, 1961-1978), due to his unique experience of Three Downs and Three Ups from 1930 to 1978; education level did not function continuously as a predictor. Three Downs and Three Ups means that over the course of his political career, Deng was removed from leadership positions three times, and then restored to the positions three times (J. Li \& Wang, 2008). This finding implies that education level as a predictor of formality should be scaled on a continuum that does not have time gaps.

The populace's education level was a negative predictor of Mao's language formality, perhaps due to a unique historical and political period in his era. The education level of Mao's audience may be negatively associated with the education level measured by the college enrollment rate. Before 1949, the predecessor of the PRC (1949 to present) was the ROC (1912-1949; J. Li \& Wang, 2008). From 1928, Chiang Kaishek gained the power of the ROC and led the Kuomintang Party. During that period, the majority of educated people served the government of the ROC, led by Chiang, because it was considered the sole legitimate government of China. Meanwhile, the majority of people led by the CPC were people from the lowest social classes, such as farmers and workers. Therefore, the higher college enrollment rate actually means that more-educated people were led by Chiang, but less-educated people were led by Mao.

After 1949, China suffered many disasters, such as the Great Proletarian Cultural Revolution (1966-1976). During the Cultural Revolution, the approach of college recruitment was not through competitive selection but recommendation by their poor family background. The recommended students were from the farmers, workers, and soldiers with lower education. The more people who were recruited by colleges at that time, the lower the incidence of education under Mao. Therefore, Mao tended to use the more peripheral route (informal discourse) when the college enrollment rate was higher because the education level of his audience was lower. This implies an impact of education level as a predictor of formality, as well.

\section{Power phase}

Results revealed that power phase was a major predictor of the language formality of leaders under the Chinese collective leadership. After they achieved power, leaders used the more formal central route to persuasion for carrying out the policies, which they proposed were different from those before they 
achieved power. For example, Mao proposed Mao Zedong Thought in his in-power times, Deng proposed Reform and Opening Up, Jiang Three Represents, and Hu the Scientific Development Concept. Another explanation is that the unique election system in the PRC indicated less power struggle between the CPC and the other minor factions. The head of state in China is elected by the National People Congress (NPC; J. Li $\&$ Wang, 2008). The NPC is a system through popular election, from township to nation, which represents democracy (O'Brien, 2008). However, this system had unavoidable deficits with regard to the chairman election, such as lack of competition and openness (Zou, 2005). The public typically had no awareness of the candidates and election system so it was unnecessary for chairman candidates in China to make public speeches in order to persuade the public to vote for them.

The analyses within power durations showed that power phase was not a consistent predictor. Power phase robustly predicted Mao's formality, but not the leaders with medium and short power durations. Power phase (before power vs. in power) predicted the language formality of leaders when power struggle existed in their in-power times. Historically, the leaders experienced different stages of the CPC development: power struggle (Mao), early power consolidation (Deng), and mature power consolidation (Jiang and $\mathrm{Hu}$ ). Since power struggle for the CPC only occurred in Mao's era, power phase was a robust predictor only for Mao's formality. Because there was no power struggle for the CPC for the leaders of the final two eras, power phase was not a powerful predictor.

It was extremely hard for Mao to maintain his power, due to the more complicated political contexts in his era. Before he gained power, Mao's talents in the military and achievements during the warring eras, such as two civil wars and the AntiJapanese War, were major factors that were attributed to his achieving power over the CPC. However, after achieving power and establishing the PRC, severe natural disasters (e.g., Three Years of Natural Disaster), inappropriate political policy (e.g., the Great Leap Forward), and overestimating internal class struggle (the Great Proletarian Cultural Revolution; J. Li \& Wang, 2008) consecutively occurred. As discrepancies on political policies and approaches to the disasters arose between Mao and his fellow leaders, his followers, and the public, Mao tended to use the central route to persuasion to win their recognition and support. This finding implies that power phase is significant predictor of the language formality of the political leaders when power struggle does prevail.

\section{Conclusions}

In this article, we tested four hypotheses that are reflected in four predictors (power phase, education level, power duration, and age) of the formality of Chinese political leaders. From the longitudinal perspective, some support emerged for each of the four hypotheses when all of the leaders were analyzed together. Specifically, leaders tended to use the more central route (formal discourse) to persuasion after achieving power than before achieving power, when the audience had higher education than lower education, when they had the shorter in-power times than longer in-power times, and when they were younger than older.

The central route allows leaders to carefully and thoughtfully consider the accuracy, evidence, reasoning, and conceptual merits of the information presented in support of their opinions, suggestions, and comments. This claim was confirmed by the increasing formality style during their in-power times, especially when the nation's education level was higher. Consequently, leaders tended to use more coherent, precise, and wellarticulated language in their persuasive messages. The leaders' language and discourse was more formal and was located primarily in the informational expository genre, with coherent logical reasoning, precisely selected words, and sentences that are syntactically and semantically complex.

In the peripheral route, leaders rely on simple cues or messages to persuade the audience, such as the attractiveness of the leaders, humor, and the frequency of presenting the message, without scrutinizing the conceptual merits of the presented information. This claim was supported by decreasing formality as a function of their increasing age and longer durations. In the peripheral route, leaders tended to use simple everyday language and tell stories in the narrative genre, with frequent words and simple syntax.

However, when leaders were classified on short, medium, and long power durations, the above predictors did not show the consistent predictability perhaps due to the complicated historical, political, and social changes for each category of leaders. Specifically, Mao tended to use the central route to persuasion after he was in power and when the nation's education level was low but his audience's education level was high, whereas he tended to use the more peripheral route as he got older. Deng's formality was only predicted by age: His formality decreased with his increasing age. The formality of leaders with a short power durations (Jiang and $\mathrm{Hu}$ ) was only predicted by education level: Formality increased with increasing education level. These findings imply that when we use power phase, education level, and age to predict the formality of the individual Chinese political leaders, we should consider the specific political and social change. The existence of power struggle is crucial for its prediction of formality. For education, it is critical to have the continuous education data to manifest its predictability. For age, the different age stages and transitions should be considered.

This research suggests that we could predict the political and social events on the basis of the formality of leaders' discourse because of these correlations between events and leaders' formality. For example, the dramatic low formality in later era of Mao was associated with the severe natural and political disasters, consisting of the Three Years of Natural Disasters, Great 
Leap Forward, and Cultural Revolution. The opposite prediction of education level for Mao's formality (negative) and the formality of Jiang and $\mathrm{Hu}$ (positive) demonstrated Mao's real audience was not the educated populace before 1949. After 1949 , even though there were more college students in Mao's era, these students were not well educated due to a series of natural and political disasters. In the current era, leaders' formality may be diagnostic of some potential unexpected events, changes in the stock market, the stability of the economy, civil discontent, or war. These claims of course need additional empirical evidence to assess their generality.

In this study, we adopted an automated measure of formality that considers multiple textual levels to examine leaders' persuasive language. The Chinese formality metric is based on advances in computational linguistics, the Chinese LIWC, Chinese LSA, and Chinese CWO (H. Li et al., 2016). Our findings showed that the Chinese formality scores were associated with the social and political events. This automated formality measure can be used for large repositories of political discourse and can therefore escalate the speed of research, rather than resorting to manual coding by humans. This measure may be adopted to analyze Chinese discourse in other genres and registers, but this is an empirical question that awaits future research.

One limitation of this study was the small number of leaders in each era. In the present study, we only analyzed the formality of paramount political leaders in China, without including any other outstanding political leaders with top leadership in the CPC. In the future, we will examine additional leaders in each generation, with different ranks in position and different times in power. Another limitation is that the analysis did not include the topics of the speeches, such as economics, war, agriculture, manufacturing, the family, and so on. Topic is presumably an important predictor of leaders' formality, especially in the current peaceful era. Future research will explore the extent to which different topics predict leaders' formality and whether their predictability changes longitudinally.

Author note This work was funded by the National Science Foundation (Grant No. BCS 0904909), by the Army Research Institute (Grant No. W91WAW-07-C-0029), and by the Minerva Initiative, Air Force Office of Scientific Research, Department of Defense (Grant No. FA9550-14-0308). Any opinions, findings, and conclusions are those of the authors and do not necessarily reflect the views of these funding agencies, cooperating institutions, or other individuals.

\section{Appendix A: List of resources for population data}

\section{Population data for 1949-2012}

National Bureau of Statistics of the People's Republic of China (www.stats.gov.cn/tjsj/zxfb/201602/t20160229_1323991.html)

\section{Population data for 1921-1948}

Ministry of Interior. (1931). 民国十七年各省市户口调查统计报告 [Statistical report of the population investigation in every province and city in the 17th year of the Republic of China]. Nanjing, China: Ministry of Interior.

Hu, H. (1935). 中国人口之分布 [Distribution of the population of the Republic of China]. Journal of Geographical Sciences, 3(2).

Bureau of Budget, Accounting, and Statistics. (1948). 中华 民国统计年鉴 [Statistical yearbook of the Republic of China]. Beijing, China: Culture Enterprises of the Republic of China.

\section{Appendix B: List of resources for college enrollment data}

\section{College enrollment data for 1949-2012}

Ministry of Education of the People's Republic of China (www. moe.edu.cn/)

\section{College enrollment data for 1970-1976}

Xia, D. (2009, December 18). 我的大学(1970-1976大学生) [My university (1970-1976 peasants and soldiers as college students)]. Retrieved from http://blog.sina.com.cn/s/blog_536 f61420100gx7y.html

\section{College enrollment data for 1921-1949}

Second Historical Archives of China. (1994). 中华民国史档案 资料汇编第五辑第一编教育(一) [History of the Republic of China, a compilation of the history of the First and Second Series of the Fifth Records: Education I \& II]. Jiangsu, China: Jiangsu Ancient Book Publishing House.

Second Historical Archives of China. (2000). 中华民国史档 案资料汇编第五辑第三编教育(一) [History of the Republic of China, a compilation of the history of the Third Series of the Fifth Records: Education I ]. Jiangsu, China: Jiangsu Ancient Book Publishing House.

Wu, X., \& Liu, S. (1933). 第一次中国教育年鉴 [First chronicle of educational events in China]. Beijing, China: Biographies Press.

\section{References}

Allen, M., \& Preiss, R. W. (1997). Comparing the persuasiveness of narrative and statistical evidence using meta-analysis. Communication Research Reports, 14, 125-131.

Arendt, H. (1970). On violence. New York: Houghton Mifflin Harcourt. Bell, A. (1984). Language style as audience design. Language in Society, 13, 145-204. 
Brennan, S. E., \& Clark, H. H. (1996). Conceptual pacts and lexical choice in conversation. Journal of Experimental Psychology: Learning, Memory, and Cognition, 22, 1482-1493. doi:10.1037/0278-7393.22.6.1482

Brown, P., \& Levinson, S. (1978). Universals in language usage: Politeness phenomena. In E. N. Goody (Ed.), Questions and politeness: Strategies in social interaction (pp. 56-289). Cambridge: Cambridge University Press.

Cheng, L. (2012). The road to Zhongnanhai: High-level leadership groups on the Eve of the 18th Party Congress. Retrieved from www.brookings. edu/research/papers/2012/01/24-china-zhongnanhai-li

Chilton, P., \& Schäffner, C. (Eds.). (2002). Politics as text and talk: Analytic approaches to political discourse. Amsterdam: Benjamins.

Clark, H. H. (1996). Using language. Cambridge: Cambridge University Press

Clark, H. H., Schreuder, R., \& Buttrick, S. (1983). Common ground at the understanding of demonstrative reference. Journal of Verbal Learning and Verbal Behavior, 22, 245-258.

Coakes, S. J., \& Steed, L. (2009). SPSS: Analysis without anguish using SPSS version 14.0 for windows. Hoboken, NJ: Wiley.

Deng, X. (2004). Collected works of Deng Xiaoping: Vols. 1-3 (Party Literature Research Center of the CPC Central Committee (2nd ed.). Beijing: People's Publishing House.

Dowell, N. M., Windsor, L. C., \& Graesser, A. C. (2015). Computational linguistics analysis of leaders during crises in authoritarian regimes. Dynamics of Asymmetric Conflict. doi:10.1080 /17467586.2015.1038286. Advance online publication.

Fang, A. C., \& Cao, J. (2009). Adjective density as a text formality characteristic for automatic text classification: A study based on the British National Corpus. In O. Kwong (Ed.), Proceedings of the PACLIC (pp. 130-139). Hong Kong, China: City University of Hong Kong Press.

Fiske, S. T., \& Taylor, S. E. (1984). Social cognition. London: Sage.

Graesser, A. C., \& McNamara, D. S. (2011). Computational analyses of multilevel discourse comprehension. Topics in Cognitive Science, 3, 371-398. doi:10.1111/j.1756-8765.2010.01081.x

Graesser, A. C., McNamara, D. S., Cai, Z., Conley, M., Li, H., \& Pennebaker, J. (2014). Coh-Metrix measures text characteristics at multiple levels of language and discourse. Elementary School Journal, 115, 210-229.

Hair, J. F., Jr., Anderson, R. E., Tatham, R. C., \& Black, W. C. (1998). Multivariate data analysis. Upper Saddle River: Prentice-Hall.

Heylighen, F., \& Dewaele, J. M. (2002). Variation in the contextuality of language: An empirical measure. Foundations of Science, 7, 293-234.

$\mathrm{Hu}, \mathrm{J}$. (2002-2012). Retrieved from http://sflrw.com/forumdisplay.php?fid=789 \&page $=1$ and www.mishuhome.com/Category_1174/Index.aspx

Huang, J., Chung, C. K., Hui, N., Lin, Y., Xie, Y., Lam, Q., \& Pennebaker, J. W. (2012). 中文版語文探索與字詞計算字典之建立 [The development of the Chinese Linguistic Inquiry and Word Count dictionary]. Chinese Journal of Psychology, 54, 185-201.

Jae, H. (2010). Syntax complexity and presentation order as determinants of comprehension in print advertisements. Journal of Promotion Management, 16, 522-532.

Jiang, Z. (2006). Collected works of Jiang Zemin: Vols. 1-3. In Party Literature Research Center of the CPC Central Committee. Beijing: People's Publishing House.

Jurafsky, D., \& Martin, J. H. (2009). Speech and language processing: An introduction to natural language processing, computational linguistics, and speech recognition. Upper Saddle River: Pearson Prentice Hall.

Kaakinen, J. K., Salonen, J., Venäläinen, P., \& Hyönä, J. (2011). Influence of text cohesion on the persuasive power of expository text. Scandinavian Journal of Psychology, 52, 201-208.

Kintsch, W. (1998). Comprehension: A paradigm for cognition. Cambridge: Cambridge University Press.

Landauer, T., McNamara, D., Dennis, S., \& Kintsch, W. (Eds.). (2007). Handbook of latent semantic analysis. Mahwah: Erlbaum.

Lee, E., \& Leets, L. (2002). Persuasive storytelling by hate groups online examining its effects on adolescents. American Behavioral Scientist, 45, 927-957.
Lei, G. (1997). 邓小平与党的第三代领导集体的形成 [Deng Xiaoping and the formation of the third generation of collective leadership]. Mao Zedong Thought Forum, 4, 4-7.

Li, H., Cai, Z., Graesser, A. C., \& Duan, Y. (2012). A comparative study on English and Chinese word uses with LIWC. In G. M. Youngblood \& P. M. McCarthy (Eds.), Proceedings of the Twenty-Fifth International Florida Artificial Intelligence Research Society Conference (pp. 238-243). Palo Alto: AAAI Press.

Li, H., Cheng, C., \& Graesser, A. C. (2015). A measure of text formality as a human construct. In I. Russel \& B. Eberle (Eds.), Proceedings of the Twenty-Eighth International Florida Artificial Intelligence Research Society Conference (pp. 175-180). Palo Alto: AAAI Press.

Li, H., Graesser, A. C., \& Cai, Z. (2013). Comparing two measures of formality. In C. Boonthum-Denecke \& G. M. Youngblood (Eds.), Proceedings of the 26th International Florida Artificial Intelligence Research Society Conference (pp. 220-225). Palo Alto: AAAI Press.

Li, H., Graesser, A. C., Conley, M., Cai, Z., Pavlik, P. I., \& Pennebaker, J. W. (2016). A new measure of text formality: An analysis of discourse of Mao Zedong. Discourse Processes, 53, 205-232. doi:10.1080/0163853 X.2015.1010191

Li, J., \& Wang, S. (2008). 中国近现代史纲要 [The outline of China's modern history]. Beijing: Higher Education Press.

Liao, X. (2012). 中共第一代中央领导集体形成过程研究一兼谈毛泽东的核心地 位是怎样确立的 [Study on formation process of the first generation of central collective leadership of the CPC-Also on how the core leadership of Mao Zedong was established]. Literature of Chinese Communist Party, 1, 43-51.

Mao, Z. (1977). Selected works of Mao Zedong: Vol. 5. In Party Literature Research Center of the CPC Central Committee. Beijing: People's Publishing House.

Mao, Z. (1991). Selected works of Mao Zedong: Vols. 1-4 (Party Literature Research Center of the CPC Central Committee (2nd ed.). Beijing: People's Publishing House.

Mao, Z. (1993). Collected works of Mao Zedong: Vols. 1-2. In Party Literature Research Center of the CPC Central Committee. Beijing: People's Publishing House.

Mao, Z. (1996). Collected works of Mao Zedong: Vols. 3-5. In Party Literature Research Center of the CPC Central Committee. Beijing: People's Publishing House.

Mao, Z. (1999). Collected works of Mao Zedong: Vols. 6-8. In Party Literature Research Center of the CPC Central Committee. Beijing: People's Publishing House.

O'Brien, K. J. (2008). Reform without liberalization: China's National People's Congress and the politics of institutional change. Cambridge: Cambridge University Press.

Pallant, J. (2013). SPSS survival manual. London: McGraw-Hill Education.

Parsons, T. (1958). Authority, legitimation and political action. In C. J. Friedrich (Ed.), Authority (pp. 28-48). Cambridge: Harvard University Press.

Pennebaker, J. W., Booth, R. J., \& Francis, M. E. (2007). Linguistic inquiry and word count: LIWC [Computer software]. Austin, TX: LIWC.net.

Petty, R. E., \& Cacioppo, J. T. (1984). The effects of involvement on responses to argument quantity and quality: Central and peripheral routes to persuasion. Journal of Personality and Social Psychology, 46, 69-81.

Petty, R. E., \& Cacioppo, J. T. (1986). The elaboration likelihood model of persuasion. Advances in Experimental Social Psychology, 19, 1-24.

Petty, R. E., Cacioppo, J. T., Strathman, A. J., \& Priester, J. R. (2005). To think or not to think: Exploring two routes to persuasion. In T. C. Brock \& M. C. Green (Eds.), Persuasion: Psychological insights and perspectives (2nd ed., pp. 81-116). Thousand Oaks: Sage.

Song, Y. (1999). 党的第二代中央领导集体形成的主要标志 [The main indicator of the formation of the second generation of central collective leadership]. Theory Studying and Exploration, 1, 12-14.

Stephan, E., Liberman, N., \& Trope, Y. (2010). Politeness and psychological distance: a construal level perspective. Journal of Personality and Social Psychology, 98, 268-280. doi:10.1037/a0016960 
Tabachnick, B. G., \& Fidell, L. S. (2001). Using multivariate statistics. New York: Harper Collins.

van Dijk, T. A. (1997). What is political discourse analysis? Belgian Journal of Linguistics, 11, 11-52.

van Dijk, T. A. (1998). Ideology: A multidisciplinary approach. London: Sage.

Wang, Y. (2005). 论第四代领导集体的”睦邻外交”思想 [On the fourth generation of collective leadership of the "good-neighbor diplomacy" thought]. Literary Circles of CPC History, 2, 20-23.
Yang, D. (2005). 中国教育制度和教育政策的变迁 [Changes of China's educational systems and polices]. Retrieved from www.aisixiang. $\mathrm{com} / \mathrm{data} / 6728 . \mathrm{html}$

Zou, P. (2005). 完善人民代表选举产生机制的若干思考一为纪念人大制度 50 周年 而作 [Thoughts on consummating election mechanism of the People's National Congress - In memory of 50th anniversary of the People's National Congress]. Law Review, 1, 17-27. 